$$
\text { "takac" — 2010/4/12 — 23:51 — page } 149 \text { - \#1 }
$$

\title{
MRP tasks, critical thinking and intrinsic motivation to proving
}

\author{
ZDENKO TAKÁČ
}

Abstract. The lack of students' need for proof is often discussed. This is an important topic, on which quite a few others have written ([26], [27], [28], [17], [8]). Nevertheless, there is limited research knowledge about how teacher can participate in process of raising of students' intrinsic motivation to proving. In this article, we discuss relationships between intrinsic motivation to proving, critical thinking and special activity - engaging with so-called MRP tasks. We present here results of a research carried out by author in two elementary schools (21 classes, grade 5-9) in Ružomberok, Slovakia. We identified the interesting relationship between students' dealing with MRP tasks and increasing of their intrinsic motivation to proving.

Key words and phrases: proof (in school mathematics), reasoning and proving, mathematics education, elementary school, intrinsic motivation (to proving), MRP tasks; critical thinking (in mathematics).

ZDM Subject Classification: E50.

\section{Theoretical framework}

The paper faces the problem of motivation to proving in students and presents some results of an experimental study developed in primary and secondary schools in Slovakia. The title of paper consists of three notions: MRP tasks - specific

The research reported here was supported in part by a grant from the Cultural and Grant Agency of the Ministry of Education of the Slovak Republic (KEGA 3/7068/09). The opinions expressed herein do not necessarily reflect the position, policy, or endorsement of the supporting agency.

Copyright (C) 2010 by University of Debrecen 


$$
\text { "takac" — 2010/4/12 — 23:51 — page } 150 \text { — \#2 }
$$

type of tasks ([23]), critical thinking and intrinsic motivation to proving. On the basis of experimental study will be discussed how they relate to each other.

\subsection{Proof, the role of proof in school mathematics and the intrinsic motivation}

Let us start with proof that is for many mathematicians a fundamental notion of mathematics. Mathematics is not just about identifying what is true or what works but also about explaining why it is true or why it works and convincing others that it is true or that it works. That is, mathematics is intrinsically about proof $([1])$.

What is mathematical proof? The traditional view is: a mathematical proof is a formal and logical line of reasoning that begins with a set of axioms and moves through logical steps to a conclusion. A proof confirms truth for a mathematician the way experiment or observation does for the natural scientist ([12]). According to Weber such views are commonly held by mathematics teachers and are passed along to students. However, many mathematics educators and some mathematicians believe that proofs are much more than this ([25]). In mathematics, especially in mathematics education, proof is not only a tool to verify the truth of a statement ([16]). For example Hanna ([15]) speaks of "proof that proves" and "proof that explain": a proof that proves shows only that a theorem is true; it provides evidential reasons alone... . A proof that explains, on the other hand, also shows why a theorem is true; it provides a set of reasons that derive from the phenomenon itself.

In the article, we understand as a proof the chain of arguments (based on intuition) stated to support the claim. In the context of our research, we do not consider formal aspect of the proof to be essential. This is in accordance with PISA competencies formulated by Mogens Niss - Reasoning mathematically:

- Following and assessing chains of arguments put forward by others.

- Knowing what a mathematical proof is (is not) and how it differs from other kinds of mathematical reasoning, e.g., heuristic.

- Uncovering the basic ideas in a given line of argument (especially a proof), including distinguishing main lines from details, and ideas from technicalities.

- Devising formal and informal mathematical arguments and transforming heuristic arguments to valid proofs, i.e., proving statements.

There is no doubt that proof plays an important role in school mathematics. Discussions are conducted on the age at which children have started to address 


$$
\text { "takac" — 2010/4/12 — 23:51 — page } 151 \text { — \#3 }
$$

this area. Many teachers believe that proof has no place in primary mathematics classrooms, because it needs to be too formal and rigorous, and young children find it difficult to follow and even harder to replicate for themselves. We disagree with this view and argue that children can be involved in ideas of proof in early age. It is an important to estimate the degree of formality and precision, we can require them. If ideas of proof are mentioned to children at quite a young age, we find that they are responsive to them and start to internalize them and to use them independently on their own initiative when they are engaged in reasoning about a mathematical problem ([2]).

The lack of students' need for proof is well-known. This is an important topic, on which quite a few others have written ([26], [27], [28], [17], [8], [13], $[13] \mathrm{t})$. In general, motivation can be defined as the process by which children's goal-directed activity is instigated and sustained ([21]). In the context of the motivation the teacher's influence is always very important. The NCTM (2000, p. 3) recommends that teachers at every level help students make, refine, and explore conjectures on the basis of evidence and use a variety of reasoning and proof techniques to confirm or disprove those conjectures. Furthermore students' concept of proof, their appreciation for its need as well as for its roles, depends on the curriculum, on the activities students are asked to carry out, on the questions they are asked and on how they are asked these questions ([8]).

Goal-directed behavior may be intrinsically motivated, extrinsically motivated, or motivated by combination of the two. Intrinsic motivation refers to the desire to participate in an activity merely for the pleasure derived from that activity $([21])$. Simply put, intrinsic motivation is when people engage in an activity without obvious external incentives, such as reward, praise or punishment. Intrinsic motivation affects human behavior and survival without being claimed for any material reward. These are activities that bring inner satisfaction, eventually are satisfactory themselves (playing, learning, scientific research, addressing their own projects). Intrinsic motivation has a touch of the human tendency to seek novelty and distraction, the inquiry skills to solve problems to contend with obstacles and manage their own lives. Since the 1970s the educational psychologists have studied intrinsic and extrinsic motivation. The numerous studies have found intrinsic motivation to be associated with high educational achievement and enjoyment by students ([6], [7], [3]). We do not want to claim that intrinsic motivation is good one and extrinsic motivation is bad one. But, in many school situations, intrinsic motivation is the best precondition for reaching educational



$$
\text { "takac" — 2010/4/12 — 23:51 — page } 152 \text { — \#4 }
$$

goals. Then it would appear to be to the benefit of all educators to understand the functioning and development of this type of motivation ([5]).

\subsection{Critical thinking}

In simple terms critical thinking is purposeful assessment about what to accept as true. Fisher and Scriven ([10]) define critical thinking as skilled, active, interpretation and evaluation of observations, communications, information, and argumentation. The term "critical" has the connotation of expressing rejection, which is not always true of critical thinking. A critical judgment of the information might conclude that it is accepted as good as it is not. More on critical thinking can be found at website of Foundation for Critical Thinking (www. criticalthinking. org/page. cfm?PageID=487\&CategoryID=73).

Schafersman ([22]) states about two different things that is all education consists of: 1. transmitting to students the subject matter and 2. transmitting to students the correct way to understand and evaluate this subject matter. Each teacher deals with the dilemma: what degree of attention paid to subject matter and what degree of attention paid to the methodology. According to Lochhead ([18]) we should be teaching students how to think, instead we are primarily teaching them what to think. This claim is valid generally, but in our opinion it is significant especially for mathematics. We do an excellent job of transmitting the content of our respective academic disciplines, but we often fail to teach students how to think effectively about this subject matter, that is, how to properly understand and evaluate it. This second ability is termed critical thinking. All educational disciplines have reported the difficulty of imparting critical thinking skills $([22])$.

Critical thinking is not exclusively mathematical notion, but mathematics is one of the best disciplines for the development of students' critical thinking. The reason for this is found in the kinds of questions mathematics asks and the nature of what it studies. Mathematics, the physical and biological sciences study phenomena that behave consistently under predictable conditions and they pose questions that can be expressed clearly and precisely, with virtually complete expert agreement ([9]). What the disciplines dealing with humans (all the social disciplines, the Arts, and the Humanities) study is often unpredictably variable.

Let us compare two above mentioned terms - critical thinking and mathematical proof. Both are attached to the verification of the new information. What is the fundamental difference? Mathematical proof is a strictly defined notion determined by the specific rules. These rules are "given from outside", they do 


$$
\text { "takac" — 2010/4/12 — 23:51 — page } 153 \text { — \#5 }
$$

not depend on person that deals with the proof - they are objective. On the contrary, critical thinking is subjective notion. The rules are "given from inside", they depend on the intellectual and psychological qualities of person. All students must do their "own thinking", their "own construction" of knowledge.

\subsection{MRP tasks}

MRP tasks (Motivation to Reasoning and Proving tasks) according to Takáč ([23]) are the tasks of following types:

Type 1: task that looks to have an easy solution, but after exhaustive dealing with problem, it has a different perhaps surprising solution.

Type 2: task that can be solved intuitively, but students are not sure of solution's correctness.

Type 3: task that has several possible solutions and students have to decide (and verify), which one is correct.

There is not sharp border of these three types of tasks. MRP tasks are not proving tasks, they do not explicitly require proof. Even dealing with most of them sense of proof does not appear. The aim of MRP tasks is "only" to weaken the solver's trust in solution on basis of guess or intuition without any verification. Furthermore, they can appear in any area of mathematics. Next are given three examples of MRP tasks and brief commentary.

MRP Task 1 (grade 7-9): John and Mary raced each other from a place $A$ to a place $B$ and back to $A$. Mary averaged $25 \mathrm{kmph}$ cycling from $A$ to $B$ and $5 \mathrm{kmph}$ walking back to $A$. John averaged $9 \mathrm{kmph}$ running from $A$ to $B$ and back to $A$. Who has won?

Teacher had recapitulated knowledge of the average speed from physics before students began engage with this task. Expected effect of the task arises, if students claim that Mary has won. There are two kinds of reasoning:

(1) With calculation - Mary has won because she averaged $(25+5) / 2=15 \mathrm{kmph}$ and John only $9 \mathrm{kmph}$.

(2) Without calculation - Mary has won because she was "much quicker" from $A$ to $B$ than John and only "little slower" from $B$ to $A$.

The reasoning "with calculation" follows from misunderstanding of term "average speed". This is a frequent fault - students do not realize that such calculation can be used only, if Mary averaged $25 \mathrm{kmph}$ and then $5 \mathrm{kmph}$ at the same time intervals (not at the same distances). The reasoning "without calculation" is 


$$
\text { "takac" — 2010/4/12 — 23:51 — page } 154 \text { — \#6 }
$$

based on an intuition. Values $25 \mathrm{kmph}, 5 \mathrm{kmph}$ and $9 \mathrm{kmph}$ of the task are chosen to students jumped to the erroneous conclusion. Reason for this fault is superficiality of students' conclusions or (like it was in first case) from misunderstanding of term "average speed".

In any case, the primary aim of addressing this task should be to practice the concept of average speed, the deeper understanding and a warning to the often inaccurate use described above. The secondary aim of the task is to make students aware that their findings should be verified before they declared to be true. Entering this task in the described experiment always led to a false solution to the students and in great surprise, when using a detailed calculation convinced that race, in fact, has won Peter. Only when the teacher asked them, students began to calculate the Mary's average speed. They were actually surprised that Mary reached an average speed of only $25 / 3 \mathrm{kmph}$.

MRP Task 2 (grade 5-9): A dog and a cat raced on the $100 \mathrm{~m}$ straight track there and back. The dog's jump is $3 \mathrm{~m}$ and the cat's jump is $2 \mathrm{~m}$ long. The cat makes 3 jumps while the dog makes 2 jumps. Who will win?

Majority of students answered in a short time: "Nobody will win (or they both will win), the dog and the cat are moving the same speed." They only discovered that the dog should go through $6 \mathrm{~m}$ (2 jumps by $3 \mathrm{~m}$ ) for the same time as a cat (3 jumps by $2 \mathrm{~m}$ ). Only few of them realized that the dog will be behind the cat after turning around at $100 \mathrm{~m}$. Only when the teacher (or successful classmate) had contradicted they started concern with the problem more consistently.

The task has very good properties to meet our goals: the situation is simple and quick to understand for students; on the basis of intuition often leads to the wrong solution; once alerted to the task's critical point (the place where the dog and cat turn), students "clearly see" their fault. The last claim can be documented by a one student's note making during the research: "How I could to confuse in such an easy task!"

MRP Task 3 (grade 5-9): A knight is on square A1 of chessboard. Is it possible to repeatedly move the knight so that it will be just once on each square of chessboard and it will finish on square H8?

It is appropriate to have the board and show students how can move a knight. Then students need time to experiment. It is an assumption that some of them will answer "yes", some will answer "no" and some will be not determined, while those who opt for one of the options ("yes" or "no") will not be sure of their 


$$
\text { "takac" — 2010/4/12 — 23:51 — page } 155 \text { — \#7 }
$$

conclusion (based on the author's personal experience with this task and the experience of the research).

In this task it is good to let students have freedom come with ideas, since this will only confirm them that they do not know with certainty what is the answer (assuming that no one finds convincing argument). Over time, it is appropriate to guide students to the proof (we use proof of concept within the meaning of proof in school mathematics). Proof has in this case particularly suitable properties for our purpose - it is so simple that it should understand and believe it really each student, on the other hand, apparently without proof students never obtain assurance on the regularity of solutions. The proof is based on the following idea: the squares A1 and H8 are dark. Knight at each move from the dark square goes to the light square, and vice versa, moving from light goes to dark. Since knight has to be just once in each square and board contains 64 squares, it must makes 63 moves. Starting on the dark square, knight must be in the light square after the odd number of movements, but $\mathrm{H} 8$ is dark. Therefore, it is not possible.

Usefulness of the problem as MRP task depends not only on the task itself, but also on the reactions of students in the class to it. To MRP task has achieved its objective, it must arise spontaneously appropriate atmosphere in the class: the students either find some solution, but feel doubts about its correctness; or find an incorrect solution, which they believe is correct (not on the numerical error); or they are unable to decide which of the possible solutions is correct. If such an atmosphere does not arise spontaneously, there is not point to force class to anything. The strength of MRP tasks is right in that the students experience a surprise at the expense of their beliefs (which are not verified, or they made a mistake in the argument) or are undecided and they want to find out which solution is correct. On the contrary, often in the teaching lesson may be that the mood created without the teacher's intention. In this case, it is good when teacher is aware of this fact and makes use of problem to be solved as a MRP task.

Note that an essential factor of Tasks 1 and 2 is in the surprise - students realize that even in seemingly simple situations can be confused if they had no verified their claim. A significant fact of Task 3 is that without verification (proof) students are not able to decide which solution is correct, but on the basis of relatively simple proof they "see it". 


\section{Purpose for the study}

We discussed a link between students' dealing with MRP tasks and their critical thinking before ([23]). On the basis of experimental study developed in schools we stated conclusion that there exists the relationship between dealing with MRP tasks and developing students' (from grade 5 to grade 9) critical thinking. This is how MRP tasks relate to critical thinking.

As mentioned above the proof is a tool to verify the truth of the statement. In this sense the aim of proof is: 1 . to convince oneself, 2 . to convince a friend or 3 . to convince "an enemy" ([20]). First item (to convince oneself) relate to critical thinking that possesses a sense of intrinsic need (motivation) to convince oneself of information's acceptability. In this view, developing of children's critical thinking raised their need to verify the truth of the statement. One can deduce that the best precondition for developing students' ability to search for logically correct arguments (proof) is that the children want to convince themselves or others. This claim is put in doubt by much of the research in mathematics education, which shows that most children are in most circumstances more convinced by examples than by a logical argument ([11], [19]). Analyzing examples can lead to a generalization, to a proof. See picture approach page 160.

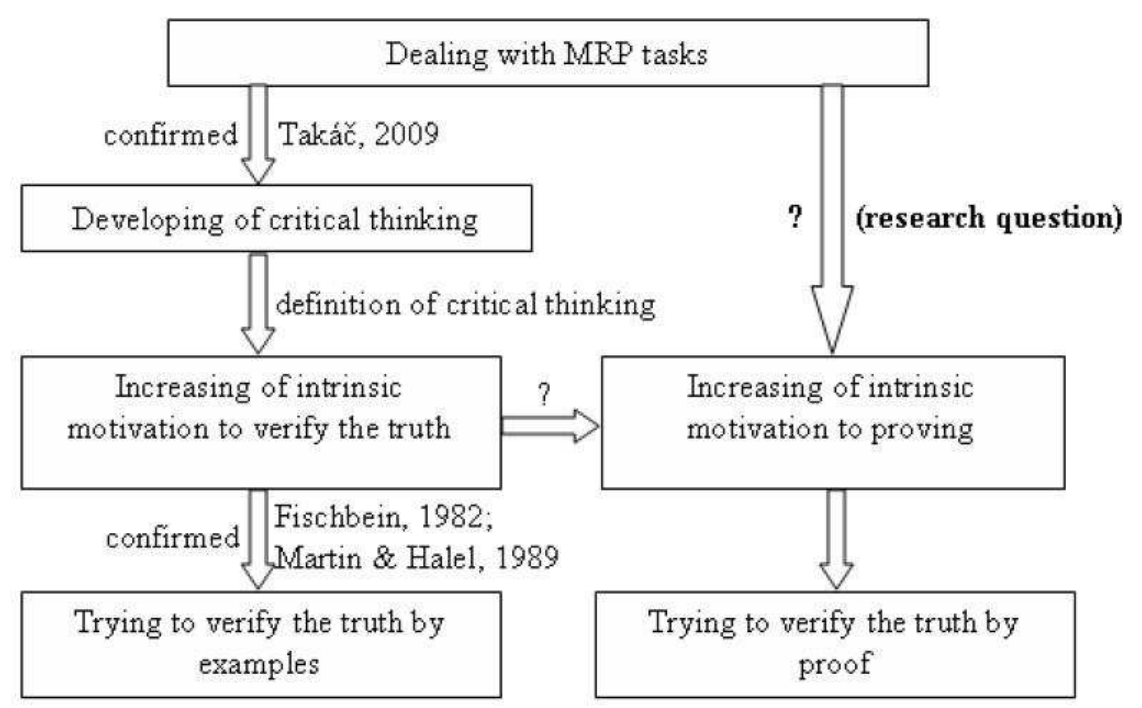




$$
\text { "takac" — 2010/4/12 — 23:51 — page } 157 \text { — \#9 }
$$

So there is no such clear and direct link between dealing with MRP tasks (developing of critical thinking) and increasing of intrinsic motivation to proving. Nevertheless, we purposed to investigate this issue. We stated the research questions: We described link between children's dealing with MRP tasks and developing of their critical thinking ([23]). Is there a link between these two issues and increasing of children's intrinsic motivation to proving? Is there an impact of dealing with MRP tasks on increasing of intrinsic motivation to proving?

\section{Research methods}

Students of classes from grade 5 to grade 9 of two primary schools (PS1 and PS2) located in Ružomberok (Slovakia) were drawn as the subjects. Mathematical results of chosen classes were average (mathematics marks) for the district. There were two classes of each school of each grade included. Each pair consisted of one experimental class and one control class with the same teacher and the same curriculum. In addition, there was one more class of grade 6 included (6EC3). Six teachers participated in observations: Adam, Bob, Cyril, Dan, Edie, Fred (pseudonyms) who teach in a primary school for 8, 12, 10, 13, 15, 6 years respectively. Next is given simple view (for example 5EC1 - 24B means that the grade 5 experimental class of the PS1 primary school had 24 students and teacher Bob):

Table 1

\begin{tabular}{|c|c|c|c|c|c|}
\hline & Grade 5 & Grade 6 & Grade 7 & Grade 8 & Grade 9 \\
\hline Experim. & $5 \mathrm{EC} 1-23 \mathrm{~B}$ & $6 \mathrm{EC} 1-23 \mathrm{~A}$ & $7 \mathrm{EC} 1-24 \mathrm{~B}$ & $8 \mathrm{EC} 1-22 \mathrm{C}$ & $9 \mathrm{EC} 1-24 \mathrm{C}$ \\
classes & $5 \mathrm{EC} 2-22 \mathrm{D}$ & $6 \mathrm{EC} 2-23 \mathrm{E}$ & $7 \mathrm{EC} 2-23 \mathrm{E}$ & $8 \mathrm{EC} 2-24 \mathrm{~F}$ & $9 \mathrm{EC} 2-25 \mathrm{D}$ \\
& $5 E C-45$ & $6 E C-46$ & $7 E C-47$ & $8 E C-46$ & $9 E C-49$ \\
& & $6 \mathrm{EC} 3-23 \mathrm{~A}$ & & & \\
\hline Control & $5 \mathrm{CC} 1-22 \mathrm{~B}$ & $6 \mathrm{CC} 1-21 \mathrm{~A}$ & $7 \mathrm{CC} 1-22 \mathrm{~B}$ & $8 \mathrm{CC} 1-22 \mathrm{C}$ & $9 \mathrm{CC} 1-21 \mathrm{C}$ \\
classes & $5 \mathrm{CC} 2-24 \mathrm{D}$ & $6 \mathrm{CC} 2-24 \mathrm{E}$ & $7 \mathrm{CC} 2-23 \mathrm{E}$ & $8 \mathrm{CC} 2-22 \mathrm{~F}$ & $9 \mathrm{CC} 2-21 \mathrm{D}$ \\
& $5 C C-46$ & $6 C C-45$ & $7 C C-45$ & $8 C C-44$ & $9 C C-42$ \\
\hline
\end{tabular}

Teachers asked students of experimental classes to engage in one or two MRP tasks a month from September of 2007 to February of 2008. Students of control classes faced the same activities as students of experimental classes except engaging in these MRP tasks. Teachers have acted the same way like they did in 


$$
\text { "takac" — 2010/4/12 — 23:51 — page } 158 \text { — \#10 }
$$

previous years of their practice and they have not made distinction between experimental and control classes. The only difference was - teachers assigned $10 \mathrm{MRP}$ tasks in experimental classes (not in control classes) during relevant six months and discussed their solutions. If need of argument emerged from the curriculum, teachers reacted in the same manner in all classes, they did not avoid discussing arguments in control classes.

\section{Data collection and analysis}

As mentioned above, teachers asked students of experimental classes to engage in one or two MRP tasks for a month during six months (10 tasks at all). Teachers included these tasks in the classroom naturally. The students perceived it as a natural part of the learning process, not as a "special activity". The problems were solved individually at first and then they were discussed by whole classroom. Teachers did not emphasize notion of proof in connection with MRP Tasks, they even purposely avoided mention of it. This was critical point of the study to obtain correct outcome.

In April and May of 2008 we tested all the subjects (post-test is described below) and then we interviewed 10 students. Five of them were selected randomly and five of them were selected keeping the rule described below. Students did not know that they are participating in a research. They have found it out only during interviews. And even then they did not know that this is related to MRP tasks which were previously dealt with in lessons.

Another procedure we chose in class 6EC3. Students of the class were asked to engage in one or two MRP tasks for a month like students of other experimental classes. But we have chosen a different procedure for testing. They were tested twice:

1. pre-test: before dealing with MRP tasks (September of 2007) and

2. post-test: after dealing with MRP tasks (May of 2008).

In both cases, we set them exactly the same tasks, as we did in other classes of grade six. According to the results we have selected 5 students and we have interviewed them.

The data for the article include the written responses of 478 students (23 of them twice) to two tasks from post-test, audio recordings and protocols of 10 interviews and teachers' reflections. The post-test consisted of one "arithmetic task" and one "geometric task". For example: 


$$
\text { "takac" — 2010/4/12 — 23:51 — page } 159 \text { — \#11 }
$$

Task 1 (post-test, arithmetic task):

Topic: The sum of two even integers, the sum of two odd integers, the sum of even and odd integers.

1. Think about the topic and take down everything you will come to mind in connection with it.

2. Imagine that you are a teacher. Write a detailed preparation of lesson, which would have dealt with this topic (You may, but need not, use the knowledge of item 1).

Task 2 (post-test, geometric task):

Topic: Quadrilateral whose vertices are midpoints of sides of rectangle.

1. Think about the topic and take down everything you will come to mind in connection with it.

2. Imagine that you are a teacher. Write a detailed preparation of lesson, which would have dealt with this topic (You may, but need not, use the knowledge of item 1).

Given topics were slightly modified in relation to the age of students. We have formulated the tasks so that the students had to solve the problem first (part 1 of task). Dealing with the arithmetic task they would note that the sum of two even integers is an even number, the sum of two odd integers is an even integer and the sum of even and odd integers is an odd integer. Dealing with the geometric task they would note that the quadrilateral with these properties is a rhombus. The students were under greater difficulties. Almost all students (94\%) were successful on the arithmetic tasks. Geometric task was somewhat more difficult, $81 \%$ of students were successful. But for us it was not an important, whether students' solution was correct. We have paid attention whether they proved their claim or not.

Furthermore, we have not addressed the question whether the proof is correct, but whether students made effort to prove the claim. The term "proof" is to be construed as any justification for their claim. But we have required the sense of a general view, not convincing by examples.

For example, there were following different approaches to the proof in arithmetic task:

(1) Algebraic approach: $2 x+2 y=2(x+y)$ (often the error occurred: $2 x+2 x=$ $4 x)$.

(2) Verbal approach: Adding a group of pairs to another group of pairs we obtain again a group of pairs. 


$$
\text { "takac" — 2010/4/12 — 23:51 — page } 160 \text { — \#12 }
$$

(3) Picture approach:

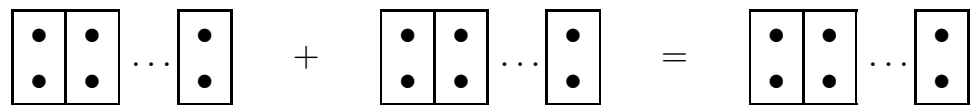

Dealing with the geometric task students used medial triangle, symmetry or congruence of triangles.

The aim of the first part of the tasks was to identify what students considered an important in connection with a specified topic. In particular, whether they included here also the proof or they did not. At the beginning of the research we have established that prospective percent growth of students' who try on the proof in the first part of the task, is due to the increased intrinsic motivation to proving. And this was one of our research criteria for assessing the relationship between dealing with MRP tasks (and developing of the critical thinking) and increasing of intrinsic motivation to proving.

The following table shows the data, which reflect the percentage of students who tried on the proof. The first number of each box concerns the first part of relevant task, the second number to the second part of the task.

Table 2

\begin{tabular}{|c|c|c|c|c|c|c|c|c|c|c|c|c|}
\hline$\%$ & \multicolumn{2}{|c|}{ Gr. 5 } & \multicolumn{2}{c|}{ Gr. 6 } & \multicolumn{2}{c|}{ Gr. 7 } & \multicolumn{2}{c|}{ Gr. 8 } & \multicolumn{2}{c|}{ Gr. 9 } & \multicolumn{2}{c|}{ Gr. 5-9 } \\
& EC & CC & EC & CC & EC & CC & EC & CC & EC & CC & EC & CC \\
\hline Arith. & 64 & 43 & 63 & 40 & 64 & 40 & 54 & 41 & 51 & 43 & 59 & 41 \\
task & 80 & 76 & 87 & 78 & 77 & 71 & 78 & 75 & 73 & 76 & 79 & 75 \\
\hline Geom. & 73 & 52 & 78 & 53 & 77 & 51 & 74 & 57 & 69 & 60 & 74 & 55 \\
task & 84 & 80 & 89 & 87 & 87 & 84 & 85 & 82 & 78 & 79 & 85 & 82 \\
\hline Ar+G & 69 & 48 & 71 & 47 & 70 & 46 & 64 & 49 & 60 & 51 & 67 & 48 \\
task & 82 & 78 & 88 & 82 & 82 & 78 & 82 & 79 & 76 & 78 & 82 & 78 \\
\hline
\end{tabular}

Let us deal with the first part of the tasks. An analysis of students' responses showed that the experimental classes of each grade (5-9) outperformed control classes of same grade on both tasks (first part). In addition, experimental classes of grade 5, 6 and 7 performed significantly better $(\alpha=0.05)$ than the control classes of the same grade. We claim that this fact shows the relationship between dealing with MRP tasks (and developing of the critical thinking) and increasing of intrinsic motivation to proving.

The aim of the second part of tasks was to find out what students considered an important from the teacher's view in connection with a specified topic. And again, in particular, whether they included here also the proof or not. We have 


$$
\text { "takac" — 2010/4/12 — 23:51 — page } 161 \text { — \#13 }
$$

examined how large the quantity of students who tried on the proof in the first part of the task is, relative to the quantity of students who mentioned the proof in the second part of the task. In other words, if the student is aware that proof is an important from teacher's view (he or she mentioned the proof in the second part of the task), does he or she consider the proof to be an important for himself (he or she tried on the proof in the first part of the task)? And this was another research criteria for assessing the relationship between dealing with MRP tasks (and developing of the critical thinking) and increasing of intrinsic motivation to proving.

Note that only three students of all respondents tried on the proof in the first part of the tasks, but did not mention it in the second part of the task. The following table shows the data, which reflect the percentage of students who tried on the proof in the first part of the task in students who mentioned the proof in the second part of the task.

Table 3

\begin{tabular}{|c|c|c|c|c|c|c|c|c|c|c|c|c|}
\hline$\%$ & \multicolumn{2}{|c|}{ Gr. 5 } & \multicolumn{2}{|c|}{ Gr. 6 } & \multicolumn{2}{c|}{ Gr. 7 } & \multicolumn{2}{|c|}{ Gr. 8 } & \multicolumn{2}{c|}{ Gr. 9 } & \multicolumn{2}{c|}{ Gr. 5-9 } \\
& EC & CC & EC & CC & EC & CC & EC & CC & EC & CC & EC & CC \\
\hline Arith. & 81 & 57 & 73 & 51 & 83 & 56 & 69 & 55 & 69 & 56 & 75 & 55 \\
\hline Geom. & 87 & 65 & 88 & 62 & 88 & 61 & 87 & 69 & 89 & 76 & 88 & 67 \\
\hline Ar+G & 84 & 61 & 80 & 57 & 86 & 59 & 79 & 62 & 79 & 66 & 82 & 61 \\
\hline
\end{tabular}

An analysis of students' responses again showed that the experimental classes of each grade (5-9) outperformed control classes of same grade on both tasks. In addition, experimental classes of grade 5, 6, 7 and 8 performed significantly better $(\alpha=0.05)$ than the control classes of the same grade. We claim that this is another fact that shows the relationship between dealing with MRP tasks (and developing of the critical thinking) and increasing of intrinsic motivation to proving.

Let us deal with the 6EC3 class. As mentioned above the class had same curriculum and deals with same activities like other experimental classes of grade 6. Unlike others, however, this class was also tested at the beginning of the research (pre-test). The pre-test and the post-test were exactly the same. An analysis of the responses showed that 10 students of 23 tried on the proof in the first part of the task in the pre-test. All of them did it also on the post-test, but there were 5 students of the rest 13 who tried on the proof in the post-test, despite they had not made it in the pre-test. We interviewed these 5 students to 


$$
\text { "takac" — 2010/4/12 — 23:51 — page } 162 \text { — \#14 }
$$

discover why they revised their opinion. Next are given parts from two interviews and their analysis. The interviewer was the class teacher Adam.

\subsection{Interview with John (pseudonym):}

1 Adam: Look at these two your answers. [Adam passed to John his start and post-tests.] You tried on the proof here, [Adam showed the post-test.] but you didn't try on the proof here. [Adam showed the pre-test.] Why?

2 John: Hmmm ... [John did not say anything, he just red his two answers and he looked a little confused.]

3 Adam: How did you proceed here? [Adam showed the post-test.]

4 John: I just put down what was on my mind.

5 Adam: And what about September test?

6 John: It was the same.

7 Adam: Yes it was. But why you tried on the proof in May, if you hadn't made it in September?

8 John: Hmmm ... I hadn't? ... I just put down [in May - post-test] what was on my mind and I wasn't thinking about what I've done in September ... maybe ... maybe something has changed ... something in my mind ... it was almost whole year.

9 Adam: What do you mean - something has changed?

10 John: I ... I don't know what has changed. I didn't know until now that I ... that I have made it so different.

11 Adam: But your two answers are almost the same. The only part that is different here is the proof. [Adam showed the post-test.]

12 John: Yes, I can see it. And isn't it an important difference?

13 Adam: Is it an important for you?

14 John: I think it is. I don't know why I didn't try on the proof in September.

John was aware of the importance of the proof in mathematics $(14,12)^{1}$. This conclusion follows also from his surprise when he realized that he had not tried on the proof in September (2, 8: "I hadn't?"). Despite of this, he tried on the proof neither in the arithmetic task nor in the geometric task of the pre-test. He

${ }^{1}$ Numbers refer to lines in the protocol.
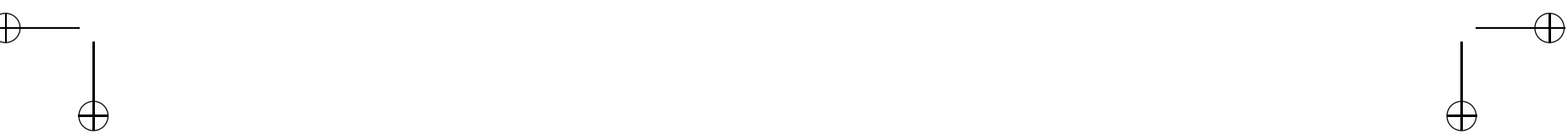


$$
\text { "takac" — 2010/4/12 — 23:51 — page } 163 \text { — \#15 }
$$

confirmed that in both cases only wrote what he considers an important $(4,6)$. Simply put, John was not aware of the importance of the proof in September (before dealing with MRP tasks), but he was aware of this fact in May (after dealing with MRP tasks). Furthermore, in his own words his view has changed (8, "maybe something has changed ... something in my mind"). Although he was confused $(8,10)$, his view of the proof is, indeed, changed after nine months. We claim that this is a consequence of his engaging with MRP tasks during this season.

\subsection{Interview with Samantha (pseudonym):}

1 Adam: Why did you try on the proof here? [Adam put Samantha's post-test on the table.]

2 Samantha: I had to take down every important thing relating to given topic. I think this is an important.

3 Adam: And why didn't you try on the proof here?" [Adam put Samantha's pre-test on the table.] Do you remember? It was in September.

4 Samantha: $\quad$ Yes I do. Hmmm ... I don't know. Maybe .... , I forgot.

5 Adam: $\quad$ Forgot?

6 Samantha: No, I couldn't forget. Hmmm ...I don't know. Maybe ... maybe I didn't consider the proof to be an important at that time.

7 Adam: $\quad$ And do you consider the proof to be an important now?

8 Samantha: Yes, I do.

9 Adam: Why?

10 Samantha: Because ... it is an important ...

11 Adam: Why do you think?

12 Samantha: Because ... hmmm ... it is an important ... hmmm ... [40 seconds silence, Samantha is hard thinking] It is like the race, we all had thought that the runner could not win and then we proved that he won. [She referred to MRP Task 1 of this article.]

13 Adam: $\quad$ Do you remember the task?

14 Samantha: Of course I do, I felt sure about my solution and I was wrong. I engaged in problem again at home. 


$$
\text { "takac" — 2010/4/12 — 23:51 — page } 164 \text { — \#16 }
$$

Samantha's view of stuff has changed similarly like John's one. She was aware of the importance of the proof in mathematics in May (2), while she was not aware of this fact in September. Her assertions indicate change of her view of the problem $(6,8)$. We emphasize that, in this case, there appeared explicitly expressed link between addressing the MRP tasks to student and her opinion of the importance of the proof (12). Samantha clearly said that she considered the proof to be an important. In despite of this, she had major problems with giving reason for her claim $(10,12)$. After long thinking she argued by giving example of situation (MRP Task 1 of this article), in which she considered the proof to be crucial. Note that Samantha's class was engaged in this task in November.

We claim that these two interviews show the relationship between dealing with MRP tasks (and developing of the critical thinking) and increasing of intrinsic motivation to proving. More about interview and analysis can be found in $[24]$.

\section{Conclusion}

We discussed a link between students' dealing with MRP tasks and their critical thinking before ([23]). On the basis of experimental study developed in schools we stated conclusion that there exists the relationship between dealing with MRP tasks and developing students' (from grade 5 to grade 9) critical thinking. This is how MRP tasks relate to critical thinking. In this article, we have explored the link between dealing with MRP tasks and increasing of intrinsic motivation to proving. The main research result is that there exists the relationship between students' dealing with MRP tasks and increasing of their intrinsic motivation to proving. We provided three different supporting arguments for this result:

(1) Data obtained from the first part of the post-test tasks showed that the students of experimental classes achieved better (grade 5, 6 and 7 significantly better, with $\alpha=0.05$ ) results than students of relevant control classes. The percentage of students, who considered the proof to be an important, was in experimental classes higher (grade 5, 6 and 7 significantly higher, with $\alpha=0.05$ ) than in control classes (see Table 1). This implies that students of experimental classes were more motivated to proving as students of control classes.

(2) The second argument follows from a comparison between the results of the first and second parts of the post-test tasks. We have assumed that in the 


$$
\text { "takac" — 2010/4/12 — 23:51 — page 165 — \#17 }
$$

second part would mention the proof students who considered the proof to be an important, and students who thought that it is considered an important by teacher (this was confirmed by the interviews and by the above described fact that only three students of all respondents tried on the proof in the first part of the tasks, but did not mention it in the second part of the task). We examined what percentage of these students considered the proof to be an important by themselves (they mentioned proof also in the first part). This percentage was in experimental classes higher (grade 5, 6, 7 and 8 significantly higher, with $\alpha=0.05$ ) than in relevant control classes (see Table 2). This, similarly to item 1 , implies that students of experimental classes were more motivated to proving as students of control classes.

(3) In despite of two previous arguments that are of quantitative sense, the third one is of qualitative sense. The analysis of above described two sections of the interviews with John and Samantha discovered that the change of students' perspective on the proof and its significance was really caused by dealing with MRP tasks. Note that students who changed their mind from September pretest to May post-test were interviewed.

Due to these three arguments we claim: there exists the relationship between students' dealing with MRP tasks and their intrinsic motivation to proving. Although we do not dare to tell about straight impact of students' dealing with MRP tasks on their intrinsic motivation to proving (on the basis of described study), we consider this relationship to be very interesting and useful in educational process.

Note that also influence of grade of students emerged in the research results. Experimental classes performed significantly better $(\alpha=0.05)$ than the control classes only of grade 5, 6 and 7 (or 5,6, 7 and 8). On the other side, experimental classes of grade 8 and 9 (or 9 ) performed better than the control classes, but not significantly better. This fact, according to Back and Pumfrey ([2]), indicates that the possibilities of teacher's participating in process of raising of intrinsic motivation to proving are better with students of lower grade, as with students of higher grade.

More research is needed to understand the way that teachers can participate in process of raising of students' intrinsic motivation to proving. In connection with MRP task new questions appeared. For example, has described increase of students' intrinsic motivation to proving long-term effect? We will search for the answer of this question in the near future. Our plane is to repeat post-test with the same classes and again to draw a comparison between experimental and control classes. 


$$
\text { "takac" — 2010/4/12 — 23:51 — page } 166 \text { — \#18 }
$$

Also other questions are to be discussed. We find useful mainly matter of transition to a higher level of formality of proof. For example, described research outcome showed increase of students' intrinsic motivation to proving. But only without forcing students to the formal aspects of proof (students proved their own way). Question is whether this increasing is present also in proving on a higher level of formality. Finally, matter of differences in results of students of various grades (from 5 to 9 ) should to be investigated more in detail.

The analysis presented in this article makes a contribution to the important topic of mathematics education - proving, particularly motivation to proving. Research results suggest a link between motivation to proving, critical thinking and MRP tasks. As mentioned above, the transition to formal proof is crucial. But this transition is very facilitated by a good pre-training ([4]). If students at an early age feel the need for proof (with the appropriate formal level), the transition to a higher formal level is easier for them ([2]). In particular, they can better keep a sense of need for proof and they will not come to believe that the proof should be done just to make a teacher happy.

\section{References}

[1] D. Almeida, Justifying and proving in the mathematics classroom, Philosophy of Mathematics Education Newsletter 9 (1996), electronic source (http://people.exeter.ac.uk/PErnest/pome/pompart8.htm).

[2] J. Back and L. Pumfrey, Primary proof?, Primary Mathematics 9, no. 2 (2005), electronic source (http://nrich.maths.org/public/viewer.php?obj_id=2838).

[3] K. C. Barrett and G. A. Morgan, Continuities and discontinuities in mastery motivation during infancy and toddlerhood, A conceptualization and review, in: Mastery motivation: Origins, conceptualization, and applications, (R. H. MacTurk and G. A. Morgan, eds.), Norwood, NJ: Ablex, 1995, 57-94.

[4] M. Billich, The use of geometric place in problem solving, in: Scientific Issues, Teaching Mathematics: Innovation, New Trends, Research, (M. Billich, M. Papčo and Z. Takáč, eds.), PF KU, Ružomberok, 2008, 7-14.

[5] M. P. Carlton and A. Winsler, Fostering Intrinsic Motivation in Early Childhood Classrooms, Early Childhood Educational Journal 25, no. 3 (1998), 159-166.

[6] E. L. Deci, Intrinsic Motivation, Extrinsic Reinforcement, and Inequity, Journal of Personality and Social Psychology 22, no. 1 (1972), 113-120.

[7] E. L. Deci and R. M. Ryan, Intrinsic motivation and self-determination in human behavior, Plenum, New York, 1985.

[8] T. Dreyfus and N. Hadas, Proof as answer to the question why, Zentralblatt für Didaktik der Mathematik 28, no. 1 (1996), 1-5. 


$$
\text { "takac" — 2010/4/12 — 23:51 — page } 167 \text { — \#19 }
$$

[9] L. Elder, Fostering Multilogical Thinking Within the Disciplines, Paper presented at The 28th Annual International Conference on Critical Thinking, Berkeley Marina, California, 2008.

[10] A. Fisher and M. Scriven, Critical Thinking: Its Definition and Assessment, Norwich, United Kingdom: Centre for Research in Critical Thinking, 1997.

[11] E. Fischbein, Intuition and proof, For the learning of mathemarics 3, no. 2 (1982), 8-24.

[12] P. A. Griffiths, Mathematics at the turn of the millennium, American Mathematical Monthly 107, no. 1 (2000), 1-14.

[13] J. Gunčaga, Das Konzept des Analysisunterrichts von Professor Igor Kluvánek einige Ergebnisse der qualitativen Forschung, Teaching Mathematics and Computer Science 5, no. 2 (2007), 349-362.

[14] J. Gunčaga and Š. Tkačik, Grundbegriffe der Analysis nach Professor Igor Kluvánek, Beiträge zum Mathematikunterricht Teil 1, Verlag Franzbecker, Berlin, 2007, 264-267.

[15] G. Hanna, Some Pedagogical Aspects of Proof, Interchange 21, no. 1 (1990), 6-13.

[16] G. Hanna and E. Barbeau, Proofs as bearers of mathematical knowledge, ZDM, The International Journal on Mathematics Education 40, no. 3 (2008), 345-353.

[17] M. Lampert, Practices and problems in teaching authentic mathematics, in: Effective and responsible teaching: The new synthesis, (F. K. Oser, A. Dick and J. Patry, eds.), Jossey-Bass Publishers, San Francisco, 1992, 295-314.

[18] J. Lochhead, An introduction to cognitive process instruction, in: Cognitive process instruction, (J. Lochhead and J. Clement, eds.), Franklin Institute Press, Philadelphia, $1-4$.

[19] W. G. Martin and G. Harel, Proof frames of preservice elementary teachers, Journal for Research in Mathematics Education 20, no. 1 (1989), 41-51.

[20] J. Mason, L. Burton and K. Stacey, Thinking Mathematically, Addison Wesley, London, 1982.

[21] P. R. Pintrich and D. H. Schunk, Motivation in education: Theory, research and applications, Englewood Cliffs, Prentice-Hall, New Jersey, 1996.

[22] S. D. Schafersman, An introducing to critical thinking, 1991, electronic source (http://www.freeinquiry.com/critical-thinking.html).

[23] Z. Takáč, Influence of MRP tasks on students' willingness to reasoning and proving, in: Proof and Proving in Mathematics Education, ICMI Study 19 Conference Proceedings, Volume 2, (F. L. Lin, F. J. Hsieh, G. Hanna and M. de Villiers, eds.), Taipei, Taiwan, 2009, 202-207.

[24] Z. Takáč, PMFA Czech Republic (to appear).

[25] K. Weber, Students' difficulties with proof, Research Sampler, Mathematical Association of America's MAA Online Website (2003), electronic source (http://www.maa.org/t_and_l/sampler/rs_8.html).

[26] V. Zack, You have to prove us wrong: Proof at the elementary school level, in: Proceedings of the Twenty-First Conference of the International Group for the 


$$
\text { "takac" — 2010/4/12 — 23:51 — page } 168 \text { — \#20 }
$$

Psychology of Mathematics Education (PME 21), Volume 4, (E. Pehkonen, ed.), Lahti, Finland, 1997, 291-298.

[27] V. Zack, Coherence in five fifth grade boys' argumentation about proof: A sociolinguistic study of the role of repetition and logical structure in the boys' talk, Paper and presentation, NCTM Research Presession, National Council of Teachers of Mathematics (NCTM) 76th Annual Meeting, Washington, D. C, 1998.

[28] V. Zack, Everyday and mathematical language in children's argumentation about proof, Educational Review 51, no. 2 (1999), Special issue: Culture and the mathematics classroom, 129-146.

ZDENKO TAKÁČ

DEPARTMENT OF MATHEMATICS

FACULTY OF EDUCATION

CATHOLIC UNIVERSITY

BYSTRICKÁ CESTA 1

03401 RUŽOMBEROK SLOVAKIA

E-mail: takac@ku.sk

(Received December, 2009) 